\title{
Asynchrony in the inter-annual recruitment of lake whitefish Coregonus clupeaformis in the Great Lakes region
}

Mitchell T. Zischke, ${ }^{\mathrm{a}, *}$, David B. Bunnell ${ }^{\mathrm{b}}$, Cary D. Troy ${ }^{\mathrm{c}}$, Eric K. Berglund ${ }^{\mathrm{d}}$, David C.

Caroffino $^{\mathrm{e}}$, Mark P. Ebener ${ }^{\mathrm{f}}, \mathrm{Ji}$ X. He ${ }^{\mathrm{g}}$, Shawn P. Sitar ${ }^{\mathrm{h}}$, and Tomas O. Höök ${ }^{\mathrm{a}}$

${ }^{a}$ Department of Forestry and Natural Resources, Purdue University, 195 Marsteller Street, West

Lafayette, IN 47907, United States

${ }^{\mathrm{b}}$ USGS Great Lakes Science Center, 1454 Green Road, Ann Arbor, MI 48105 United States

${ }^{\mathrm{c}}$ Lyles School of Civil Engineering, Purdue University, 550 Stadium Mall Drive, West Lafayette, IN

47907, United States

${ }^{\mathrm{d}}$ Ontario Ministry of Natural Resources and Forestry, Suite 221e, 435 James St, Thunder Bay ON

P7E6S8, Canada

${ }^{\mathrm{e}}$ Michigan Department of Natural Resources, 96 Grant St, Charlevoix, MI 49720, United States

${ }^{\mathrm{f}}$ Chippewa Ottawa Resource Authority, 179 W. Three Mile Road, Sault Ste. Marie, MI 49783, United

States

${ }^{\mathrm{g}}$ Michigan Department of Natural Resources, 160 E. Fletcher, Alpena, MI 49707, United States

${ }^{\mathrm{h}}$ Michigan Department of Natural Resources, 484 Cherry Creek Rd, Marquette MI 49885, United

States

*Corresponding Author: Tel.: +1 (404) 229-2260; Fax: +1 (765) 496-2422; email:

mitchell.zischke@gmail.com

(C) 2017. This manuscript version is made available under the Elsevier user license http://www.elsevier.com/open-access/userlicense/1.0/ 


\section{Abstract}

Spatially separated fish populations may display synchrony in annual recruitment if the factors that drive recruitment success, particularly abiotic factors such as temperature, are synchronised across broad spatial scales. We examined inter-annual variation in recruitment among lake whitefish (Coregonus clupeaformis) populations in lakes Huron, Michigan and Superior using fishery-dependent and -independent data from 1971-2014. Relative year-class strength (RYCS) was calculated from catchcurve residuals for each year class across multiple sampling years. Pairwise comparison of RYCS among datasets revealed no significant associations either within or between lakes, suggesting that recruitment of lake whitefish is spatially asynchronous. There was no consistent correlation between pairwise agreement and the distance between datasets, and models to estimate the spatial scale of recruitment synchrony did not fit well to these data. This suggests that inter-annual recruitment variation of lake whitefish is asynchronous across this broad region. While our method primarily evaluated year-to-year recruitment variation, it is plausible that recruitment of lake whitefish varies at coarser temporal scales (e.g. decadal). Nonetheless, our findings differ from research on some other Coregonus species and suggest that local biotic or density-dependent factors may contribute strongly to lake whitefish recruitment rather than inter-annual variability in broad-scale abiotic factors.

Key words: Age-at-length, e-folding Scale, Erie, Huron, Michigan, Superior 


\section{Introduction}

Fish recruitment, defined as the number of fish that survive to enter a fishery, is a measure of the annual reproductive success of a population and is typically highly variable (Hilborn and Walters, 1992). Recruitment variability is influenced by the life history of each species and is strongly mediated by biotic and abiotic factors both within and external to the system (Houde and Hoyt, 1987; Myers et al., 1995). In species that have high fecundity, small egg size, small larval size at hatch and no parental care, recruitment may often be regulated at an early larval stage; whereas, in species with an opposite suite of traits, recruitment may be regulated during later life stages (Houde, 1994; Houde and Hoyt, 1987). For example, species that have small larvae may display highly variable recruitment (i.e., 'boom' and 'bust' years) driven by high mortality due to changes in abiotic factors (e.g., periods of unfavourable temperature; Houde, 1994; Myers et al., 1997). In contrast, species that have larger, more developed larvae may express less variable recruitment that is influenced by biotic factors such as spawning-stock size and density-dependent effects on juveniles (Houde and Hoyt, 1987).

While most studies have evaluated temporal variability in recruitment within a system, recruitment also varies spatially; and populations may show temporal synchrony in recruitment patterns over varying spatial scales. The mechanisms of possible synchrony may include: dispersal of young fish across populations (Chevalier et al., 2014; Ranta et al., 1998), similar population dynamics of adults or juveniles (e.g., similar responses to a broadly distributed predator, competitor, or prey; Liebhold et al., 2004), and consistent responses to a broad scale environmental factor (e.g., annual climate conditions; Phelps et al., 2008; Tedesco et al., 2004). In 
species where recruitment is primarily driven by local biotic factors (e.g., spawningstock biomass or predation), recruitment dynamics tend to vary at relatively fine 'local' scales (Pritt et al., 2014). In contrast, for those species where recruitment is primarily driven by abiotic factors (e.g., temperature), recruitment may vary over much broader spatial scales (Myers et al., 1997). Moran's theorem (also known as the 'Moran effect') states that the spatial correlation of population variation will equal the spatial correlation of environmental cues (Moran, 1953). While abiotic factors influence population dynamics at local scales, abiotic factors may also be correlated across locations separated by large geographic distances, which may synchronise population dynamics (including recruitment) at these same spatial scales.

The 'Moran effect' has been observed in a number of populations including fishes (Hudson and Cattadori, 1999). In a review that utilised datasets from 19 fish species in different systems, Myers et al. (1997) observed a wide range of spatial scales for recruitment synchrony $(1-1000 \mathrm{~km})$, with mean values for marine and freshwater species differing by an order of magnitude (500 v. $50 \mathrm{~km}$, respectively). Myers et al. (1997) suggested that broad-scale environmental variables (e.g., wind) might drive recruitment synchrony in marine systems, whereas local-scale biotic variables (e.g., predation) may be more important in freshwater systems. Differences in larval dispersal and life history strategies may have also contributed to the drastic differences in the scale of recruitment synchrony in these systems (Houde, 1994; Myers et al., 1997; Winemiller, 2005).

The Laurentian Great Lakes represent unique freshwater systems that have broad scale climate and environmental characteristics similar to marine systems. Some Great Lakes fish species (e.g., yellow perch Perca flavescens) display population dynamics and life history traits similar to many marine species (as generalized by 
Houde, 1994), while other species (e.g., lake trout Salvelinus namaycush) have traits that are more typical of freshwater fishes (Ludsin et al., 2014; Winemiller, 2005; Winemiller and Rose, 1992). Species-specific recruitment dynamics and the drivers behind these dynamics are far less studied in the Great Lakes than in marine systems (Ludsin et al., 2014; Pritt et al., 2014), and recent studies suggest that recruitment synchrony may occur at spatial scales similar to marine systems (Bunnell et al., 2010; Myers et al., 2015). For example, while Myers et al. (1997) estimated that yellow perch display recruitment synchrony at distances less than $15 \mathrm{~km}$, recent research in Lakes Michigan, Huron, Erie and Ontario suggest synchrony at a scale up to $150 \mathrm{~km}$ that is partially driven by mean spring-summer temperature (Honsey et al., 2016; Zhang et al. in press). Bloater Coregonus hoyi populations display decadal recruitment synchrony at spatial scales up to $800 \mathrm{~km}$ across lakes Superior, Michigan and Huron (Bunnell et al., 2010). Cisco C. artedi populations also display broad spatial synchrony in recruitment of up to $400 \mathrm{~km}$ among the Great Lakes and inland lakes in Minnesota, thought to be driven by environmental factors such as maximum wind speed during larval emergence, rather than dispersal (Myers et al., 2015).

Understanding of recruitment dynamics and potential for recruitment synchrony in other Coregonus species in the Great Lakes, including lake whitefish C. clupeaformis, is limited. Lake whitefish is a native species of the Great Lakes and inland lakes throughout a large region of temperate North America. The species has been important to indigenous and commercial fisheries for hundreds of years, and the recent average annual harvest from commercial fisheries in the Great Lakes has exceeded 7,000 t (Ebener et al., 2008; Madenjian et al., 2006). The stock structure of lake whitefish in the Great Lakes is still somewhat unresolved, but may consist of at least 56 stocks that vary in their spatial size and movement patterns (Ebener et al., 
2008). Lake whitefish spawn in the late-fall (e.g. Nov-Dec) in shallow nearshore rocky areas, depositing large $(\sim 3 \mathrm{~mm})$ eggs on the substrate. Eggs hatch in late winter and spring (e.g. Feb-Apr); and after hatch, large ( 13mm), well-developed larvae begin feeding in shallow littoral areas through July, and move to slightly deeper nearshore areas when the water warms (Claramunt et al. 2010a; Veneranta et al. 2013). Given that whitefish larvae are large and well-developed at hatching, biotic and density-dependent factors may have high influence on their recruitment success, as suggested by previous research that showed spawning-stock biomass can affect lake whitefish recruitment success (Brown et al., 1993; Taylor et al., 1987). However, research has also suggested that abiotic factors such as fall wind intensity, fall and spring water and air temperature, and the presence and timing of ice cover, can affect lake whitefish recruitment (Brown et al., 1993; Christie, 1963; Freeberg et al., 1990; Lawler, 1965; Taylor et al., 1987). Given the limited understanding of lake whitefish recruitment dynamics including recruitment synchrony in the Great Lakes, the aims of this study were to: i) use historical catch-at-age data to explore inter-annual recruitment synchrony of lake whitefish in the Great Lakes, and ii) if inter-annual synchrony exists, estimate the spatial scale of synchrony to better understand the recruitment dynamics of lake whitefish in the Great Lakes.

\section{Materials and methods}

\section{Lake whitefish datasets}

Catch-at-age data for lake whitefish were compiled from lakes Huron, Michigan and Superior for the period 1971-2014 (Fig. 1). These data were obtained from 
fisheries agencies in the region. The main gear types used to sample whitefish were gill nets and trap nets. For different datasets, whitefish ages were estimated using scales, a combination of scales and otoliths, otoliths only or pectoral fin rays.

Temporal and spatial coverage, gear type and ageing method varied among datasets. Different ageing methods are known to lead to different age estimates for lake whitefish, with methods using scales consistently leading to younger age estimates, particularly for larger fish (Herbst and Marsden, 2011; Muir et al., 2008a,b; Zhu et al., 2015). We split datasets by the ageing method used, resulting in four groups of datasets: scales only, a combination of scales and otoliths, otoliths only, and pectoral fin rays only (Tables 1-4). In the case of some data provided by the Chippewa Ottawa Resource Authority (CORA), both scales and otoliths were used for age interpretation, with the final age assigned to the highest age estimate from both structures. To avoid potential bias, all analyses and comparisons were conducted on each ageing method separately. Different sampling methods (i.e., fishery-dependent or fishery-independent) and gears (i.e., trap nets or gill nets) are likely to catch fish of different ages, which may bias estimates of recruitment based on age-based catch curves. Therefore, within each of the four groups of data, we split each group by the sampling method and gear used. Given that our objective was to determine the spatial scale of inter-annual recruitment synchrony, we also split data groups by designated lake whitefish management units (Tables 1-4; Ebener et al., 2008).

The protocols outlined above resulted in 23 datasets where fish were aged using scales (Table 1), 14 datasets where fish were aged using a combination of scales and otoliths (Table 2), 4 datasets where fish were aged using otoliths (Table 3), and 4 datasets where fish were aged using pectoral fin rays (Table 4). These datasets had a broad range of sample sizes (from a minimum of 962 to a maximum of 160,423) and 
year classes (1966-2009), and spanned 25 different lake whitefish management units throughout lakes Huron, Michigan and Superior (Tables 1-4; Fig. 1).

\section{Relative year-class strength}

Relative year-class strength (RYCS) was used as an index of recruitment success for whitefish. We used an age-based catch-curve method for estimating RYCS (Maceina, 1997). This method fits an exponential model to catch-at-age data, with fish age as the independent variable and relative abundance as the dependant variable. Relative abundance was calculated by taking the proportional composition of each age class (i.e., the number of fish aged in each age class divided by the total number of fish aged in the sample) within each dataset and year (Honsey et al. 2016). Relative abundance was positively skewed and therefore log-transformed prior to analysis (Honsey et al. 2016). A weighted linear model with age-specific abundance (logtransformed) as a weighting factor was used in favour of a standard linear model to mediate the influence of older, less abundant fish on the analysis (Maceina, 1997).

Age classes that were not fully recruited to the sampling gear in each dataset and year were removed prior to fitting the linear model (Haddon, 2010). The age of fish when fully recruited to the sampling gear was identified as the age class with the highest abundance in each sampling year. The age class with the highest abundance was the first age used in fitting the catch curve to catch-at-age data and was allowed to vary among years within each dataset. Age at full recruitment was allowed to vary to incorporate changes in whitefish growth and environmental conditions (which likely affect catchability) through time. We excluded data from years having fewer than 150 age estimates as done by Honsey et al. (2016). 
Residuals from the weighted linear model (i.e., observed minus predicted values) were calculated for five year-classes (i.e., the age at full recruitment + four subsequent ages) in each sampling year (Honsey et al., 2016). Residual values generally displayed skewed distributions. Therefore, rather than calculating the mean residual for each year class across sampling years, which may result in one year driving the mean value, we calculated the proportion of sampling years for each year class that had positive residuals to provide an overall indication of RYCS. For example, if 3 of 5 sampling years had positive residual values, the RYCS is 0.6. To ensure RYCS numbers had both positive and negative values (i.e., to represent strong and weak RYCS, respectively), we subtracted 0.5 from each proportion, as 0.5 would be expected with neutral year-class strength. This resulted in values for RYCS that ranged from -0.5 (weak) to 0.5 (strong) for each year class. RYCS was only calculated for year classes that had residual values from at least three sampling years. The total number of sampling years used to calculate RYCS for each year class was variable. This was because the age when fish were fully recruited varied among sampling years, which resulted in certain year classes to be more common than others across sampling years. Estimating RYCS from multiple years builds on the approach of Maceina (1997), which only estimated year-class strength from one sampling year. Using multiple survey years should provide more robust indices of true year-class strength that is less susceptible to biases in sampling from year to year.

RYCS is an index of recruitment success relative to year classes immediately preceding or following a particular year class. As such, this method should index inter-annual recruitment variation (e.g., year to year boom-and-bust dynamics), but will not capture coarser (e.g., decadal) temporal scale variation. Lack of information 
on relative abundances for most of the whitefish populations modelled, as well as temporal trends in age at full recruitment to gear (see below), precluded other analytical approaches to assess coarser temporal scale recruitment variation (e.g., Bunnell in press; Myers et al. 1997)

\section{Pairwise comparison of RYCS}

To compare RYCS estimates (i.e., values ranging from -0.5 to 0.5) among datasets, we calculated the Spearman's rank correlation coefficient $(\rho)$ for each pairwise comparison. This resulted in values ranging from -1 to 1 , whereby the absolute value refers to the correlation between two datasets (i.e., -1 and 1 are both highly correlated) and the sign (i.e., negative or positive) refers to the direction of correlation between datasets. For the purposes of our pairwise comparison, we identified strong negative and positive correlations as -1.00 to -0.50 and 0.50 to 1.00 , respectively, and relatively weak correlations as -0.50 to 0.50 . If lake whitefish populations show recruitment asynchrony, the distribution of $\rho$ values should represent a normal distribution, centered on 0. We used a one-sample Kolmogorov-Smirnov test to compare the distributions of $\rho$ to a normal distribution. We also used a one-sample ttest to compare mean $\rho$ values to the expected mean of 0 (if recruitment is asynchronous). To compare distributions of $\rho$ among analyses (i.e., $\rho$ within lake and between lakes), we used a two-sample Kolmogorov-Smirnov test.

To explore the spatial scale of correlation among datasets, we categorized pairwise comparisons into three groups for each ageing structure: 1) comparisons between lakes (e.g. datasets from Lakes Huron and Superior), 2) comparisons within lakes but between non-neighbouring management units (e.g. datasets from WFH-04 and WFH- 
07), and comparisons within lakes and between neighbouring management units (e.g. datasets from WFH-06 and WFH-07).

Spatial scale of recruitment synchrony

The spatial scale of recruitment synchrony of lake whitefish in the Great Lakes region was estimated by fitting an exponential decay model to $\rho$ values from pairwise comparisons (Honsey et al., 2016; Myers et al., 1997). This method estimated the distance required to reduce pairwise agreement by a factor of $\mathrm{e}^{-1}$ (known as the efolding scale) by fitting the following model:

$$
\rho=e^{-\left(\frac{d}{v}\right)}
$$

where $\rho$ is Spearman's rank correlation coefficient, $d$ is the great circle distance between the centroid of the sampling locations (e.g., management unit) and $v$ is the efolding scale. The model was fit using non-linear least squares weighted by the number of overlapping years between datasets, and comparisons were only made between datasets that had overlapping estimates of RYCS for at least five years. All analyses were performed in $\mathrm{R}$ version 3.1.1 (R Core Team, 2014).

\section{Results}

Age at full recruitment 
Mean age of fish when fully recruited to fishing (or sampling) gear varied by ageing structure and through time. Fish aged using otoliths had a higher mean age than fish aged using other structures (Fig. 2). Mean age was 4-6 years for fish aged using scales and 10-13 years for fish aged using otoliths, and remained relatively consistent through time for both ageing structures (Fig. 2). In contrast, mean age was 7-9 years for fish aged using a combination of scales and otoliths, and 5-8 years for fish aged using pectoral fin rays, and increased from the early 2000s to 2014 for these ageing structures (Fig. 2). Temporal trends of mean age at full recruitment were similar when datasets were split by lake or sampling gear. Given these differences in mean age at full recruitment through time, our approach of allowing age at full recruitment to vary among sampling years was appropriate to reduce bias in estimates of RYCS.

\section{Annual trends in RYCS}

For the ageing structures examined, there were no clear trends in RYCS among datasets (Fig. 3). For most year classes, an approximately equal number of datasets had positive and negative RYCS (i.e. both strong and weak recruitment in each year class among datasets). With the exception of a few year-classes, the magnitude of positive and negative RYCS was consistent across year classes. There were also no clear trends when comparing datasets within or between lakes, and comparing across ageing structures (Fig. 3). For example, for year classes 1985-1995, 33-71\% of datasets had positive RYCS and 23-56\% of datasets had negative RYCS, depending on the year class (Fig 3a). Also, a relatively similar number of datasets from lakes Huron Michigan had positive and negative RYCS during 1985-1995 (Fig 3a.) 


\section{Pairwise comparison of RYCS}

Pairwise comparison of RYCS among datasets across all three ageing structures suggests that recruitment is asynchronous among whitefish populations. From datasets where fish were aged using scales, mean (S.D.) $\rho$ was $0.01(0.42)$, which did not differ from 0 (one-sample t-test: $t=0.16, d f=172, p=0.88$ ), and the distribution of $\rho$ values was normal (one-sample Kolmogorov-Smirnov: $D=0.05$, $p=0.68$; Fig. 4a). Pairwise comparisons between lakes yielded a mean (S.D.) $\rho$ of $0.04(0.44)$, while comparisons within lakes but among dissimilar datasets yielded a mean (S.D.) $\rho$ of -0.07 (0.39) and comparisons within lakes and among similar datasets yielded a mean (S.D.) $\rho$ of 0.20 (0.43). All three mean $\rho$ values did not differ from $0(p=0.12-0.38)$. Similarly, all three distributions of $\rho$ were not significantly different from each other (two-sample Kolmogorov-Smirnov tests: $p=0.11-0.63)$.

From datasets where fish were aged using a combination of scales and otoliths, mean (S.D.) $\rho$ was $-0.01(0.37)$, which did not differ from $0(t=-0.30, d f=75, p=0.76)$, and the distribution of $\rho$ values was normal $(D=0.11, p=0.28$; Fig. 4b). Pairwise comparisons between lakes yielded a mean (S.D.) $\rho$ of -0.05 (0.39), while comparisons within lakes but among dissimilar datasets yielded a mean (S.D.) $\rho$ of 0.03 (0.36) and comparisons within lakes and among similar datasets yielded a mean (S.D.) $\rho$ of 0.09 (0.34). All three mean $\rho$ values did not differ from $0(p=0.28-0.85)$. Similarly, all three distributions of $\rho$ were not significantly different from each other (two-sample Kolmogorov-Smirnov tests: $p=0.29-0.95$ ). 
From datasets where fish were aged using otoliths, only one pairwise comparison (between datasets $\mathrm{O} 1$ and $\mathrm{O} 2$ in Lake Huron) had >4 overlapping year classes; its $\rho$ value was -0.55 , which we considered a strong negative correlation.

From datasets where fish were aged using pectoral fin rays, there were a total of six pairwise comparisons. From these, mean (S.D.) $\rho$ was $0.15(0.36)$, which did not differ from $0(t=1.05, d f=5, p=0.34)$, and the distribution of $\rho$ values was normal ( $D=0.25, p=0.77$; Fig. $4 \mathrm{c})$. The low number of comparisons did not provide sufficient power to compare between and within lakes.

Spatial scale of recruitment synchrony

There was no clear trend between $\rho$ values and the distance between datasets (Fig. 5). Exponential decay models did not fit well to these data and estimates of the efolding scale (i.e., parameter $v$ in the model) had large error. Specifically, the efolding scale (S.E.) was $8.22(12.30) \mathrm{km}$ for fish aged using scales, $9.28(18.56) \mathrm{km}$ for fish aged using a combination of scales and otoliths, and $85.16(29.78) \mathrm{km}$ for fish aged using pectoral fin rays. Fish aged using otoliths were not included in the analysis due to an insufficient number of pairwise comparisons. The lack of trend in the data and poor fit of the models supports our other findings that recruitment in lake whitefish may be asynchronous, or that any potential synchrony is only likely to occur at fine spatial scales.

\section{Discussion}

Recruitment asynchrony in lake whitefish 
In the Great Lakes region from 1968 to 2009, lake whitefish year-class strength displayed little pairwise agreement among datasets, suggesting asynchronous interannual recruitment variation of lake whitefish. An earlier study examined year-class strength of lake whitefish from commercial catches, and while year-class strength varied through time, this variation was not synchronised among regions (Lawler, 1965). More recently, an analysis of lake whitefish populations in the Great Lakes reported that growth has decreased through time due to the establishment of dreissenid mussels, but trends were inconsistent among regions, suggesting that these populations may not be synchronized at broad spatial scales (Fera et. al. 2015). Given the relatively large size of lake whitefish eggs, they may have adequate energy reserves to mitigate changes in temperature. These temperature changes may also be relatively minimal as lake whitefish eggs develop during winter under the ice. Temperature and ice cover have been suggested as potential drivers of lake whitefish recruitment in some regions (Brown et al., 1993; Christie, 1963; Freeberg et al., 1990; Taylor et al., 1987). However, if these abiotic factors are not synchronized across broad spatial scales, or if separate populations respond differently to these abiotic factors, these factors may not result in recruitment synchrony. Lynch et al. (2015) found that environmental variables such as temperature, wind speed and ice cover help explain recruitment variability in 8 of 13 lake whitefish management units in the upper Great Lakes. However, these abiotic factors affected recruitment in each management unit to a different degree (i.e., both positive and negative affects), suggesting there may be minimal recruitment synchrony among management units despite synchrony in abiotic factors. Similarly, Myers et al. (1997) reported that 
recruitment synchrony in freshwater fishes may be limited to proximate populations despite abiotic variables correlating over broader spatial scales.

As broad-scale spatial synchrony was not observed in this study, it is likely that lake whitefish recruitment is driven more so by spatiotemporal overlap with biotic factors than abiotic factors. One such biotic factor may be spawning stock abundance, which has been shown to be more important than spring temperatures in predicting lake whitefish recruitment in northern Lake Michigan (Brown et al., 1993). The large size and rapid development of first-feeding larvae may result in a higher resilience to starvation, as has been shown for a number of marine and freshwater fish larvae (Miller et al., 1988). Also, given that larval lake whitefish develop relatively early and reach the juvenile stage before spring spawning species (e.g., walleye), they may experience little interspecific competition for food. Once at the juvenile stage, population dynamics (e.g., density dependence) and other biotic factors may drive recruitment more strongly than biotic and abiotic factors acting on eggs and larvae (Claramunt et al., 2010; Houde 1994; Houde and Hoyt, 1987). Furthermore, lake whitefish grow for many years before they are fully recruited to the fisheries examined in this study (e.g. age at full recruitment was as high as 16 years old in some datasets). During this time, populations experience a wide range of biotic and abiotic factors that may influence recruitment and RYCS. These factors may cause substantial inter-population variation in recruitment, rather than recruitment synchrony among populations. This lack of synchrony may result in lake whitefish recruitment being relatively stable at broad spatial scales (e.g. lake-wide), as populations with weak recruitment in a particular year may be offset by other populations with strong recruitment (e.g., portfolio effect; Schindler et al., 2010). 
Our analysis purposely examined annual variation in recruitment, rather than variation in recruitment over longer time periods, owing to two factors: a) to minimize the potential bias of non-stationarity in lake whitefish growth and b) because data availability limited other analyses (e.g. Bunnell et al., 2006, 2010; Myers et al., 1997). It may be that recruitment in lake whitefish is less variable on a year-to-year basis, thus limiting the potential for annual recruitment synchrony, but is more variable over multiple years where weak and strong year-classes persist to affect harvest and growth across populations. The latter hypothesis may explain the broad-scale temporal changes that have occurred in whitefish populations across the Great Lakes. For example, abundance of the 1972-2010 year classes at age-4 was considerably larger in northern lakes Huron and Michigan than other areas, as estimated from statistical catch-at-age analysis in management units encompassed by our study (Fig. 6; Modeling Subcommittee, Technical Fisheries Committee, 2014). Recruitment in northern lakes Huron and Michigan simultaneously increased through time, peaking between 1993 and 2001 and then declined precipitously thereafter, whereas recruitment of lake whitefish was more consistent in other Lake Michigan and all Lake Superior management units (Fig. 6; Modeling Subcommittee, Technical Fisheries Committee, 2014). Although year-class strength was not particularly synchronized between management units, the increases in recruitment from the early 1970s to the late 1990s and then precipitous decline thereafter suggests that largescale biotic or abiotic factors were having a similar effect on lake whitefish recruitment across a fairly broad geographic area. Broad-scale ecosystem change may also cause recruitment asynchrony of lake whitefish populations in the Great Lakes. For example, dreissenid mussels are associated with the decline of Diporeia spp. (Nalepa et al., 2009), one of the primary prey for lake whitefish. Given that Diporeia 
spp. temporal dynamics have also varied across lakes Superior (not impacted), Michigan (declining since early 1990s; Nalepa et al., 2009) and Huron (likely declining in early 2000s; Nalepa et al. 2007), it is likely that these invasions impacted spatially distinct lake whitefish populations at different times, which could contribute to the recruitment asynchrony observed in this study. This highlights the complexity of exploring recruitment synchrony among lake whitefish populations across the Great Lakes.

\section{Comparison between lake whitefish and other species}

Our results align with the results of a number of studies on two Coregonus species that display recruitment asynchrony in lakes in Scandinavia. Populations of vendace C. albula display varying year-class strength among lakes, which is thought to be driven by nutrient levels, adult condition, ice cover and air temperature (Axenrot and Degerman, 2015; Linløkken and Sandlund, 2015; Sandström et al., 2014). Populations of European whitefish $C$. lavaretus also display varying year-class strength among lakes, driven by similar factors as vendace, as well as water levels (Linløkken and Sandlund, 2015; Sandström et al., 2014). Species-specific differences in the drivers of year-class strength between these two species are thought to be due to differences in the spawning habitat, as vendace spawn in deeper, offshore waters compared to whitefish (Linløkken and Sandlund, 2015). Despite abiotic factors (e.g., temperature) contributing to year-class strength in these species, both vendace and whitefish did not display within species recruitment synchrony among lakes in close proximity to each other (Axenrot and Degerman, 2015; Sandström et al., 2014), suggesting population-specific responses to these factors. One difference between these studies 
and our study is that the Great Lakes are larger than these Scandinavian lakes, and may have different physical and biological processes acting on fish populations.

Recent studies have reported much broader spatial scales of recruitment synchrony for some species in the Great Lakes, including two Coregonus species (i.e., cisco and bloater) that are closely related, and have somewhat similar life histories as lake whitefish. All three species have relatively large eggs $(2-3 \mathrm{~mm})$ and first-feeding larvae (10-13 mm), but cisco and lake whitefish spawn at similar times (e.g., NovDec) and places (i.e., nearshore) whereas bloater spawn later (e.g.., Feb-Mar) and in deeper offshore waters (Auer, 1982; Scott and Crossman, 1973). From 1978 through 2006, bloater exhibited a spatial scale of recruitment synchrony of up to $800 \mathrm{~km}$ in the Great Lakes, with climate variation identified as the most parsimonious explanation (Bunnell et al., 2010). Since 2008, however, bloater recruitment in Lake Huron has dramatically increased while no comparably strong recruitment signal has been detected in Lakes Superior or Michigan (Gorman and Weidel, 2015). Biotic factors such as the sex ratio of mature adults, adult condition, and the biomass of egg (e.g. sculpins) and larval (e.g. alewife) predators could be underlying the differences in these populations (Bunnell et al., 2006, 2014; Collingsworth et al., 2014). The other Coregonus species, cisco, has been reported to have broad spatial recruitment synchrony between Lake Superior and inland lakes, with maximum wind speed during the larval period hypothesised to be the explanatory factor (Myers et al., 2015). Myers et al. (2014) also suggested that food availability during the larval stage may significantly influence the year-class strength of cisco in Lake Superior. These three congeners in the Great Lakes appear to exhibit different scales and durations of recruitment synchrony, despite some commonalities in their life history characteristics. Based on their relatively large sizes of eggs and larvae, Coregonus 
recruitment may be expected to be influenced by biotic factors during late larval or juvenile periods more than abiotic factors during egg or larval periods (Houde, 1994). Future research is required to understand the mechanisms by which climate can influence Coregonus recruitment and potentially even synchronise their populations.

It is somewhat difficult to compare recruitment synchrony among species from various studies because these studies used a wide range of methods to determine yearclass strength. For example, Bunnell et al. (2010) constructed correlograms of bloater CPUE from trawl surveys; whereas,Myers et al. (2015) combined acoustic methods with midwater-trawl and gillnet data to estimate relative abundance-at-age and RYCS of cisco. If non-stationarity is an issue with the population and recruitment dynamics of these species (as may be the case for lake whitefish), changes in size-at-age may influence estimates of year-class strength. As such, the estimates of recruitment synchrony reported for bloater and cisco may not be comparable to the estimates for lake whitefish in this study. In contrast, Honsey et al. (2016) used methods almost identical to this study, which may allow for more meaningful comparisons between species. Honsey et al. (2016) estimated a spatial scale of recruitment synchrony of $150 \mathrm{~km}$ for yellow perch in the Great Lakes. Yellow perch have different life history traits than lake whitefish, with spring spawning, smaller eggs and smaller first feeding larvae (Auer, 1982; Ludsin et al., 2014). Hence, yellow perch may be more influenced by climate variables than lake whitefish, and one might expect a broader spatial scale of recruitment synchrony for yellow perch. Nevertheless, it suggests that the method used in our study is likely to be appropriate for detecting inter-annual recruitment synchrony if it was evident in catch-at-age data.

\section{Limitations and future research}


The historical catch-at-age data used in our analyses were estimated using different methods by fisheries agencies in the Great Lakes region. Fish were sampled using both fishery-dependent and -independent methods, using various gears with different sizes and arrangements of mesh on gill nets and trap nets, and lake whitefish ages were estimated using different ageing structures. We observed substantial differences in mean age at full recruitment among ageing structures, which may bias the age estimates used to index RYCS. A number of studies have reported less biased age estimates for lake whitefish using otoliths (Herbst and Marsden, 2011; Mohr and Nalepa, 2005; Muir et al., 2008a,b; Zhu et al., 2015). We separated datasets by the ageing structures used to estimate age, and our analysis of datasets where lake whitefish were aged using scales and otoliths yielded similar results to datasets where fish were aged using scales only. This provides strong evidence that lake whitefish display asynchrony in inter-annual recruitment variability, despite potential biases with some ageing structures. Future collaboration among fisheries agencies to conduct standardised sampling and age estimation would facilitate greater opportunities for researchers to understand spatiotemporal population dynamics of lake whitefish in the Great Lakes.

The mean age at which lake whitefish were fully recruited to fishing and sampling gears increased through time. For example, the mean age of fish aged using scales and otoliths or pectoral fin rays increased from the early 2000s to 2014, which may suggest an overall decrease in the size-at-age for lake whitefish across many of the Great Lakes. This supports previous findings that the growth dynamics of many lake whitefish stocks have changed from large, fast growing fish to slow-growing fish that reach a smaller size and have poorer condition, likely due to a combination of 
ecosystem alterations caused by dreissenid mussels (Mohr and Nalepa, 2005) and density-dependent growth reductions (Ebener et al. 2008; Kratzer et al. 2007a; Fera et al. 2015). To account for this variation, we modified methods of Maceina (1997) and Honsey et al. (2016) to allow age at full recruitment to vary on an annual basis. Given that non-stationarity in lake whitefish population dynamics is likely, the approach of evaluating RYCS on an annual basis for each dataset may reduce the impact of longterm changes in lake whitefish biology on our analysis. Allowing age at full recruitment to vary each year is also likely to account for temporal changes in sampling methods or gear.

The datasets used in this analysis were divided into the management units used by each fisheries agency. However, these management units may not accurately represent the stock structure of lake whitefish. For example, there are 25 lake whitefish management units in Lake Huron, but there may only be six discrete lake whitefish stocks (Eberts et al. 2017). In contrast, genetics, morphometrics and life history traits have been used to infer at least 56 stocks of lake whitefish throughout the Great Lakes (Casselman et al., 1981; Ebener et al., 2008; Imhof et al., 1980; Stott et al., 2004; VanDeHey et al., 2009), which is higher than the number of lake whitefish management units in the region. Some lake whitefish stocks may exist at fine spatial scales, while some may move hundreds of kilometres (Ebener et al., 2008). If recruitment was synchronised among multiple populations within a single management unit, then we may not have been able to detect such synchrony in the analysis. However, this would still suggest that the spatial scale of synchrony in lake whitefish is relatively fine in the Great Lakes. Furthermore, different stocks of lake whitefish may display different life history traits and population dynamics that could result in different recruitment dynamics and drivers to abiotic and biotic factors 
(Claramunt et al., 2010; Ihssen et al., 1981; Wang et al., 2008), which may also cause the lack of recruitment synchrony seen in this study.

Overall, there is a relatively small body of literature on recruitment synchrony in freshwater species, particularly those in the Great Lakes region. Given environmental and ecological processes in the Great Lakes are atypical of freshwater systems, future research should examine recruitment synchrony from more species and populations in these systems, particularly in light of the contrasting results of this study when compared to other research. It would be useful to examine the diversity and extent of recruitment synchrony among even more Great Lakes fishes to better understand the drivers of synchrony, and identify whether broad-scale synchrony is typical or atypical among Great Lakes fishes. This greater understanding may lead to improved management of fish and fisheries in the region.

\section{Conclusions and implications for management}

Our study has shed light on the population and recruitment dynamics of lake whitefish in the Great Lakes over the past 40 years. Size-at-age has consistently decreased among lake whitefish populations, which aside from potentially impacting our analysis of recruitment synchrony, also has implications for fisheries management. This non-stationarity in population dynamics due primarily to changes in ecosystem dynamics (e.g., establishment of dreissenid mussels) will affect stock assessments that are used to evaluate lake whitefish populations and set harvest limits (Ebener et al. 2005). The non-stationarity in age and growth of lake whitefish has been recognized by stock assessment groups in the Great Lakes and these groups have incorporated time-varying growth and selectivity into stock assessments (Modeling 
Subcommittee, Technical Fisheries Committee, 2014). These time-varying growth and selectivity functions should be incorporated into all stock assessments being developed in the Great Lakes basin.

The results from our study suggest that lake whitefish do not exhibit inter-annual recruitment synchrony at spatial scales relevant to managers or ecologists. These dynamics appear to differ from other species in the Great Lakes. Density-dependent and local biological factors may drive recruitment (and juvenile survival) in lake whitefish, and should be the focus of future research and management efforts for the species.

\section{Acknowledgements}

First, we would like to acknowledge fisheries agencies in the Great Lakes region for collecting catch-at-age data for lake whitefish over the last 40 years. We thank all staff at these agencies that provided data for this project, including those data that were not ultimately used in this manuscript. These staff includes C. Davis, A. Cottrill, A. Cook and L. Witzel (OMNR), J. Markham (NY DEC), C. Vandergoot and A. Gorman (OH DNR), and J. Myers (WI DNR). We would like to thank A. Lynch (USGS) and three anonymous reviewers for providing critical feedback that greatly improved the quality of the manuscript. We also thank members of the Purdue Fish Ecology Lab for comments on an earlier version of this manuscript. This project was funded by the Great Lakes Fishery Commission project number 2012_TRO_44022. 


\section{References}

Auer, N.A., 1982. Identification of Larval Fishes of the Great Lakes Basin with Emphasis on the Lake Michigan Drainage. Great Lakes Fishery Commission, Ann Arbor, MI. Special Publication 82-3, 744pp.

Axenrot, T., Degerman, E., 2015. Year-class strength, physical fitness and recruitment cycles in vendace (Coregonus albula). Fish. Res. 173, 61-69. doi:10.1016/j.fishres.2015.03.017.

Brown, R.W., Taylor, W.W., Assel, R.A., 1993. Factors affecting the recruitment of lake whitefish in two areas of northern Lake Michigan. J. Great Lakes Res. 19, 418-428.

Bunnell, D.B., Adams, J.V., Gorman, O.T., Madenjian, C.P., Riley, S.C., Roseman, E.F., Schaeffer, J.S., 2010. Population synchrony of a native fish across three Laurentian Great Lakes: evaluating the effects of dispersal and climate. Oecologia. 162, 641-651. doi: 10.1007/S00442-0091-4 87-6.

Bunnell, D.B., Höök, T.O., Troy, C.D., Liu, W., Madenjian, C.P., Adams, J.V., In press. Testing for synchrony in recruitment among four Lake Michigian fish species. Can. J. Fish. Aquat. Sci. doi: 10.1139/cjfas-2015-0534.

Bunnell, D.B., Madenjian, C.P., Croley II, T.E., 2006. Long-term trends of bloater (Coregonus hoyi) recruitment in Lake Michigan: evidence for the effect of sex ratio. Can. J. Fish. Aquat. Sci. 63, 832-844.

Bunnell, D.B., Mychek-Londer, J.G., Madenjian, C.P., 2014. Population-level effects of egg predation on a native planktivore in a large freshwater lake. Ecol. Freshw. Fish. 23, 604-614. doi: 10.1111/eff.12112. 
Casselman, J.M., Collins, J.J., Grossman, E.J., Ihssen, P.E., Spangler, G.R., 1981. Lake whitefish (Coregonus clupeaformis) stocks of the Ontario waters of Lake Huron. Can. J. Fish. Aquat. Sci. 38, 1772-1789.

Chevalier, M., Laffaille, P., Grenouillet, G., 2014., Spatial synchrony in stream fish populations: influence of species traits. Ecography. 37, 960-968. doi: 10.1111/ecog.00662.

Christie, W.J., 1963. Effects of artificial propagation and the weather on recruitment in the Lake Ontario whitefish fishery. J. Fish. Board Can. 20, 597-646.

Claramunt, R.M., Muir, A.M., Johnson, J., Sutton, T.M., 2010a. Spatio-temporal trends in the food habits of age-0 lake whitefish. J. Great Lakes Res. 36, 66-72. doi: 10.1016/j.jglr.2010.01.002.

Claramunt, R.M., Muir, A.M., Sutton, T.M., Peeters, P.J., Ebener, M.P., Fitzsimons, J.D., Koops, M.A., 2010b. Measures of larval lake whitefish length and abundance as early predictors of year-class strength in Lake Michigan. J. Great Lakes Res. 36, 84-91. doi:10.1016/j.jglr.2010.02.005.

Collingsworth, P.D., Bunnell, D.B., Madenjian, C.P., Riley, S.C., 2014. Comparative recruitment dynamics of alewife and bloater in Lakes Michigan and Huron. Trans. Am. Fish. Soc. 143, 294-309. doi: 10.1080/00028487.2013.833986.

Ebener, M.P., Bence, J.R., Newman, K.R., Schneeberger, P.J., 2005. Application of statistical catch-at-age models to assess lake whitefish stocks in the 1836 treatyceded waters of the upper Great Lakes, in: Mohr, L.C., Nalepa, T.F., Proceedings of a workshop on the dynamics of lake whitefish (Coregonus clupearformis) and the amphipod Diporeia spp. in the Great Lakes. Great Lakes Fishery Commission Technical Report 66. 310pp. 
Ebener, M.P., Kinnunen, R.E., Schneeberger, P.J., Mohr, L.C., Hoyle, J.A., Peeters, P., 2008. Management of commercial fisheries for lake whitefish in the Laurentian Great Lakes of North America, in: Schechter, M.G., Leonard, N.J., Taylor, W.W., International governance of fisheries ecosystems: learning from the past, finding solutions for the future. American Fisheries Society, Bethesda, Maryland. ISBN: 978-1-888569-99-5.

Eberts, R.L., Wissel, B., Simpson, G.L., Crawford, S.S., Stott, W., Hanner, R.H., Manzon, R.G., Wilson, J.Y., Boreham, D.R., Somers, C.M., 2017. Isotopic Structure of Lake Whitefish in Lake Huron: Evidence for Regional and Local Populations Based on Resource Use. N. Am. J. Fish. Manag. 37, 133-148. doi: 10.1080/02755947.2016.1245225.

Feiner, Z.S., Bunnell, D.B., Höök, T.O., Madenjian, C.P., Warner, D.M., Collingsworth, P.D., 2015. Non-stationary recruitment dynamics of rainbow smelt: The influence of environmental variables and variation in size structure and lengthat-maturation. J. Great Lakes Res. 41, 246-258. doi: 10.1016/j.jglr.2014.11.029.

Fera, S.A., Rennie, M.D., Dunlop, E.S. 2015. Cross-basin analysis of long-term trends in the growth of lake whitefish in the Laurentian Great Lakes. J. Great Lakes Res. 41, 1138-1149. doi: 10.1016/j.jglr.2015.08.010.

Freeberg, M.H., Taylor, W.W., Brown, R.W., 1990. Effect of egg and larval survival on year-class strength of lake whitefish in Grand Traverse Bay, Lake Michigan. Trans. Am. Fish. Soc. 119, 92-100.

Gobin, J., Lester, N.P., Cottrill, A., Fox, M.G., Dunlop, E.S., 2015. Trends in growth and recruitment of Lake Huron lake whitefish during a period of ecosystem change, 1985 to 2012. J. Great Lakes Res. 41, 405-414. doi: 10.1016/j.jglr.2015.03.003. 
Gorman, O.T., Weidel, B.C., 2015. Great Lakes prey fish populations: a cross-basin overview of status and trends based on bottom trawl surveys, 1978-2014. Report to the Upper and Lower Lakes Committee Meetings, Great Lakes Fishery Commission, March 23-27, 2015. Available: http://www.glfc.org/lakecom/common_docs/Compiled\%20Reports\%20from\%20U

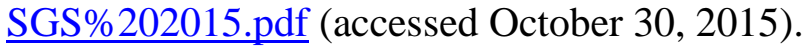

Haddon, M., 2010. Modelling and quantitative methods in fisheries, second edition. CRC press, Boca Raton. ISBN 9781584885610

Herbst, S.J., Marsden, J.E., 2011. Comparison of precision and bias of scale, fin ray, and otolith age estimates for lake whitefish (Coregonus clupeaformis) in Lake Champlain. J. Great Lakes Res. 37, 386-389. doi: 10.1016/j.jglr.2011.02.001.

Hilborn, R., Walters, C.J., 1992. Quantitative fisheries stock assessment: Choice, dynamics, and uncertainty. Chapman and Hall Inc., New York.

ISBN: 9781402018459.

Honsey, A.E., Bunnell, D.B., Troy, C.D., Fielder, D.G., Thomas, M.V., Knight, C.T., Chong, S.C., Höök, T.O., 2016. Recruitment synchrony of yellow perch (Perca flavenscens, Percidae) in the Great Lakes Region, 1966-2008. Fish. Res. 181, 214221. doi: 10.1016/j.fishres.2016.04.021.

Houde, E.D., 1994. Differences between marine and freshwater fish larvae: implications for recruitment. ICES J. Mar. Sci. 51, 91-97.

Houde, E.D., Hoyt, R.D., 1987. Fish early life dynamics and recruitment variability. Am. Fish. Soc. Symp. 2, 17-29.

Hudson, P.J., Cattadori, I.M., 1999. The Moran effect: a cause of population synchrony. Trends in Ecology \& Evolution. 14, 1-2. 
Ihssen, P.E., Evans, D.O., Christie, W.J., Reckahn, J.A., DesJardine, R.L., 1981. Life history, morphology, and electrophoretic characteristics of five allopatric stocks of lake whitefish (Coregonus clupeaformis) in the Great Lakes region. Can. J. Fish. Aquat. Sci. 38, 1790-1807.

Imhof, M., Leary, R., Booke, H.E., 1980. Population or stock structure of lake whitefish, Coregonus clupeaformis, in northern Lake Michigan as assessed by isozyme electrophoresis. Can. J. Fish. Aquat. Sci. 37, 783-793.

Kratzer, J. F., Taylor, W.W., Ferreri, C.P., Ebener, M.P., Jankun, M., Brzuzan, P., Hliwa, P., Luczynski, M. 2007a. Factors affecting growth of lake whitefish in the upper Laurentian Great Lakes. Adv. Limnol. 60, 459-470.

Kratzer, J.F., Taylor, W.W., Turner, M. 2007b. Changes in fecundity and egg lipid content of lake whitefish (Coregonus clupeaformis) in the upper Laurentian Great Lakes between 1986-87 and 2003-05. J. Great Lakes Res. 33, 922-929.

Lawler, G.H., 1965. Fluctuations in the success of year-classes of whitefish populations with special reference to Lake Erie. J. Fish. Board Can. 22, 1197-1227. Liebhold, A., Koenig, W.D., Bjørnstad, O.N., 2004. Spatial synchrony in population dynamics. Annu. Rev. Ecol. Evol. Syst. 35, 467-490. doi: 10.2307/annurev.ecolsys.34.011802.30000.

Linløkken, A.N., Sandlund, O.T., 2015. Recruitment of sympatric vendace (Coregonus albula) and whitefish (C. lavaretus) is affected by different environmental factors. Ecol. Freshw. Fish. doi: 10.1111/eff.12243.

Ludsin, S.A., DeVanna, K.M., Smith, R.E., 2014. Physical--biological coupling and the challenge of understanding fish recruitment in freshwater lakes. Can. J. Fish. Aquat. Sci. 71, 775-794. doi: 10.1139/cjfas-2013-0512. 
Lynch, A.J., Taylor, W.W., Beard, T.D., Lofgren, B.M., 2015. Climate change projections for lake whitefish (Coregonus clupeaformis) recruitment in the 1836 Treaty Waters of the Upper Great Lakes. J. Great Lakes Res. 41, 415-422. doi: 10.1016/j.jglr.2015.03.015.

Maceina, M.J., 1997. Simple application of using residuals from catch-curve regressions to assess year-class strength in fish. Fish. Res. 32, 115-121.

Madenjian, C.P., O'Connor, D.V., Pothoven, S.A., Schneeberger, P.J., Rediske, R.R., O'Keefe, J.P., Bergstedt, R.A., Argyle, R.L., Brandt, S.B., 2006. Evaluation of a lake whitefish bioenergetics model. Trans. Am. Fish. Soc. 135, 61-75. doi:10.1577/T04-215.1.

Miller, T.J., Crowder, L.B., Rice, J.A., Marschall, E.A., 1988. Larval size and recruitment mechanisms in fishes: Toward a conceptual framework. Can. J. Fish. Aquat. Sci. 45, 1657-1670.

Modeling Subcommittee, Technical Fisheries Committee, 2014. Technical Fisheries Committee Administrative Report 2014: Status of Lake Trout and Lake Whitefish Populations in the 1836 Treaty-Ceded Waters of Lakes Superior, Huron and Michigan, with Recommended Yield and Effort Levels for 2014. Available at: http://www.michigan.gov/greatlakesconsentdecree

Mohr, L.C., Nalepa, T.F., 2005. Proceedings of a workshop on the dynamics of lake whitefish (Coregonus clupeaformis) and the amphipod Diporeia spp. in the Great Lakes. Great Lakes Fishery Commission Technical Report No. 66, Ann Arbor, MI. Moran, P.A.P., 1953. The statistical analysis of the Canadian Lynx cycle. Australian J. Zool. 1, 291-298. 
Muir, A.M., Ebener, M.P., He, J.X., Johnson, J.E., 2008a. A Comparison of the Scale and Otolith Methods of Age Estimation for Lake Whitefish in Lake Huron. N. Am. J. Fish. Manag. 28, 625-635. doi: 10.1577/M06-160.1

Muir, A.M., Sutton, T.M., Peeters, P.J., Claramunt, R.M., Kinnunen, R.E. 2008b. An Evaluation of Age Estimation Structures for Lake Whitefish in Lake Michigan: Selecting an Aging Method Based on Precision and a Decision Analysis. N. Am. J. Fish. Manag. 28, 1928-1940. doi: 10.1577/M08-014.1

Myers, R.A., Barrowman, N.J., Thompson, K.R., 1995. Synchrony of recruitment across the North Atlantic: an update. (Or, "now you see it, now you don't!"). ICES J. Mar. Sci. 52, 103-110.

Myers, R.A., Mertz, G., Bridson, J., 1997. Spatial scales of interannual recruitment variations of marine, anadromous, and freshwater fish. Can. J. Fish. Aquat. Sci. 54, $1400-1407$.

Myers, J.T., Yule, D.L., Jones, M.L., Ahrenstorff, T.D., Hrabik, T.R., Claramunt, R.M., Ebener, M.P., Berglund, E.K., 2015. Spatial synchrony in cisco recruitment. Fish. Res. 165, 11-21.

Myers, J.T., Yule, D.L., Jones, M.L., Quinlan, H.R., Berglund, E.K., 2014. Foraging and predation risk for larval cisco (Coregonus artedi) in Lake Superior: a modelling synthesis of empirical survey data. Ecol. Model. 294, 71-83. doi: 10.1016/j.ecolmodel.2014.09.009.

Nalepa, T.F., Fanslow, D.L., Lang, G.A., 2009. Transformation of the offshore benthic community in Lake Michigan: Recent shift from the native amphipod Diporeia spp. to the invasive mussel Dreissena rostriformis bugensis. Freshw. Biol. 54, 466-479. 
Nalepa, T.F., Fanslow, D.L., Pothoven, S.A., Foley III, A.J., Lang, G.A., 2007. Longterm trends in benthic macroinvertebrate populations in Lake Huron over the past four decades. J. Great Lakes Res 33, 421-436

Phelps, Q.E., Graeb, B.D.S., Willis, D.W., 2008. Influence of the Moran Effect on Spatiotemporal Synchrony in Common Carp Recruitment. Trans. Am. Fish. Soc. 137, 1701-1708. doi: 10.1577/T07-108.1.

Pritt, J.J., Roseman, E.F., O'Brien, T.P., 2014. Mechanisms driving recruitment variability in fish: comparisons between the Laurentian Great Lakes and marine systems. ICES J. Mar. Sci. 71, 2252-2267. doi:10.1093/icesjms/fsu080.

R Core Team, 2014. R: A language and environment for statistical computing. $\mathrm{R}$ Foundation for Statistical Computing, Vienna, Austria. url: http://www.Rproject.org.

Ranta, E. Kaitala, V., Lundberg, P., 1998. Population variability in space and time: the dynamics of synchronous population fluctuations. Oikos. 83, 376-382.

Sandström, A., Ragnarsson-Stabo, H., Axenrot, T., Bergstrand, E., 2014. Has climate variability driven the trends and dynamics in recruitment of pelagic fish species in Swedish Lakes Vänern and Vättern in recent decades? Aquat. Ecosyst. Heal. Manag. 17, 349-356. doi: 10.1080/14634988.2014.975668.

Schindler, D. E., Hilborn, R., Chasco, B., Boatright, C.P., Quinn, T.P., Rogers, L.A., Webster, M.S., 2010. Population diversity and the portfolio effect in an exploited species. Nat. 465, 609-612. doi: 10.1038/nature09060.

Scott, W.B., Crossman, E.J., 1973. Freshwater fishes of Canada. Bulletin 184, Freshwater Research Board of Canada, Ottawa.

Stott, W., Todd, T.N. Kallemeyn, L., 2004. Genetic variability among lake whitefish from Isle Royale and the upper Great Lakes. Annales Zoologici Fennici. 41, 51-59. 
Taylor, W.W., Smale, M.A., Freeberg, M.H., 1987. Biotic and Abiotic Determinants of Lake Whitefish (Coregonus ciupeaformis) Recruitment in Northeastern Lake Michigan. Can. J. Fish. Aquat. Sci. 44, s313-s323.

Tedesco, P.A., Hugueny, B., Paugy, D., Fermon, Y., 2004. Spatial synchrony in population dynamics of West African fishes: a demonstration of an intraspecific and interspecific Moran effect. J. Animal Ecol. 73, 693-705.

VanDeHey, J.A., Sloss, B.L., Peeters, P.J., Sutton, T.M., 2009. Genetic structure of lake whitefish (Coregonus clupeaformis) in Lake Michigan. Can. J. Fish. Aquat. Sci. 66, 382-393. doi:10.1139/F08-213.

Veneranta, L., Hudd, R., Vanhatalo, J., 2013. Reproduction areas of sea-spawning coregonids reflect the environment in shallow coastal waters. Mar. Ecol. Prog. Ser. 477, 231-250. doi: 10.3354/meps10169.

Wang, H.-Y., Höök, T.O., Ebener, M.P., Mohr, L.C., Schneeberger, P.J., 2008. Spatial and temporal variation of maturation schedules of lake whitefish (Coregonus clupeaformis) in the Great Lakes. Can. J. Fish. Aquat. Sci. 65, 21572169. doi:10.1139/F08-124.

Winemiller, K.O., 2005. Life history strategies, population regulation, and implications for fisheries management. Can. J. Fish. Aquat. Sci. 62, 872-885. doi: 10.1139/F05-040.

Winemiller, K.O., Rose, K.A. 1992., Patterns of life-history diversification in North American fishes: implications for population regulation. Can. J. Fish. Aquat. Sci. 49, 2196-2218.

Zhang, F., Reid, K.B., Nudds, T.D. In press. Relative effects of biotic and abiotic factors during early life history on recruitment dynamics: a case study. Can. J. Fish. Aquat. Sci. doi: 10.1139/cjfas-2016-0155. 
Zhu, X., Wastle, R.J., Howland, K.L., Leonard, D.J., Mann, S., Carmichael, T.J.,

Tallman, R.F., 2015. A Comparison of Three Anatomical Structures for Estimating Age in a Slow-Growing Subarctic Population of Lake Whitefish. N. Am. J. Fish.

Manag. 35, 262-270. doi: 10.1080/02755947.2014.996683 


\section{List of Tables:}

Table 1. The 23 datasets used in an analysis of recruitment synchrony in lake whitefish that were aged using scales. For source, OMNR=Ontario Ministry of Natural Resources, CORA=Chippewa Ottawa Resource Authority, and MIDNR=Michigan Department of Natural Resources. For management unit, WFH = Whitefish Huron, GB=Georgian Bay, MB=Main Basin, NC=North Channel, WFS=Whitefish Superior, QMA=Quota management area. For gear, G=gill nets, and $\mathrm{T}=$ trap nets. For sampling, FD=fishery-dependent, and FI=fishery-independent. $\mathrm{n}=$ sample size for each dataset. Number (n) fish contributing to the analysis.

Table 2. The 14 datasets used in an analysis of recruitment synchrony in lake whitefish that were aged using scales and otoliths. For source, CORA=Chippewa Ottawa Resource Authority. For management unit, WFH=Whitefish Huron, and WFM=Whitefish Michigan. For gear, $\mathrm{G}=$ gill nets, and $\mathrm{T}=$ trap nets. For sampling, $\mathrm{FD}=$ fishery-dependent, and $\mathrm{FI}=$ fishery-independent. $\mathrm{n}=$ sample size for each dataset.

Table 3. The four datasets used in an analysis of recruitment synchrony in lake whitefish that were aged using otoliths. For source, OMNR=Ontario Ministry of Natural Resources, and MIDNR=Michigan Department of Natural Resources. For management unit, WFH=Whitefish Huron, and QMA=Quota management area. For gear, $\mathrm{G}=$ gill nets, and $\mathrm{T}=$ trap nets. For sampling, $\mathrm{FD}=$ fishery-dependent. $\mathrm{n}=$ sample size for each dataset.

Table 4. The 4 datasets used in an analysis of recruitment synchrony in lake whitefish that were aged using pectoral fin rays. For source, MIDNR=Michigan Department of 
Natural Resources. For management unit, WFM=Whitefish Michigan, and WFS=Whitefish Superior. For gear, T=trap nets. For sampling, FD=fisherydependent. $\mathrm{n}=$ sample size for each dataset. 


\section{Figure captions}

Fig. 1. A map of the Great Lakes showing the management units for lake whitefish. These include whitefish Huron (WFH), whitefish Michigan (WFM) and whitefish Superior (WFS) used by the Michigan Department of Natural Resources (MIDNR) and the Chippewa Ottawa Resource Authority (CORA), and Lake Superior quota management areas (QMA) and Lake Huron main basin (MB), Georgian Bay (GB) and north channel (NC) used by the Ontario Ministry of Natural Resources. Management units used in our analysis (see Tables 1-4) are indicated by grey shading.

Fig. 2. The mean and standard error fish age (years) when fully recruited to sampling gear for each year class, separated by ageing structure (i.e., scales, scales and otoliths, otoliths or pectoral fin rays). Age at full recruitment was determined by the peak in proportional composition in the catch curves.

Fig. 3. Relative year-class strength (calculated from catch-curve residuals) from a) 23 datasets where fish were aged using scales, b) 14 datasets where fish were aged using scales and otoliths and c) 4 datasets where fish were aged using otoliths and 4 datasets where fish were aged using pectoral fin rays (see Tables 1-4). Positive values indicate relatively strong recruitment and negative values indicate relatively weak recruitment. Different groups of colours represent different lakes, with yellow, gold and brown indicating datasets from Lake Huron, red and pink indicating datasets from Lake Michigan and blue and green indicating datasets from Lake Superior. 
Fig. 4. Frequency distribution of Spearman's rank correlation coefficient values from pairwise comparisons of datasets between lakes (dark grey bars), within lakes but between datasets from non-neighboring management units (light grey bars) and within lakes and between datasets from neighboring management units (black bars) for fish aged using a) scales, b) a combination of scales and otoliths, and c) pectoral fin rays (Tables 1-3). The number of pairwise comparisons in each category is indicated in parentheses. The dashed lines distinguish strong negative (-1.00 to -0.50$)$, neutral (0.50 to 0.50$)$ and strong positive (0.50 to 1.00$)$ correlations.

Fig. 5. A comparison of the distance $(\mathrm{km})$ between datasets and the pairwise proportional agreement of RYCS $\left(P_{\mathrm{a}}\right)$ for fish aged using a) scales, b) a combination of scales and otoliths, and c) pectoral fin rays (Tables 1-4). Each point represents a single pairwise comparison and the size of the point indicates number of overlapping year classes used in the comparison $(n=5-38)$. The solid line displays the model fitted to the data to estimate the e-folding scale. The e-folding scale (i.e., spatial scale of recruitment synchrony) was estimated as $8.22,9.28$ and $85.16 \mathrm{~km}$ for each dataset, respectively.

Fig. 6. Model estimates of the numbers of age-4 fish from each year class recruited to the commercial fishery in Lakes Huron (a-b), Michigan (c-i) and Superior (j-m; Modeling Subcommittee, 2014). Note that the scale of the y-axis differs among some plots. 


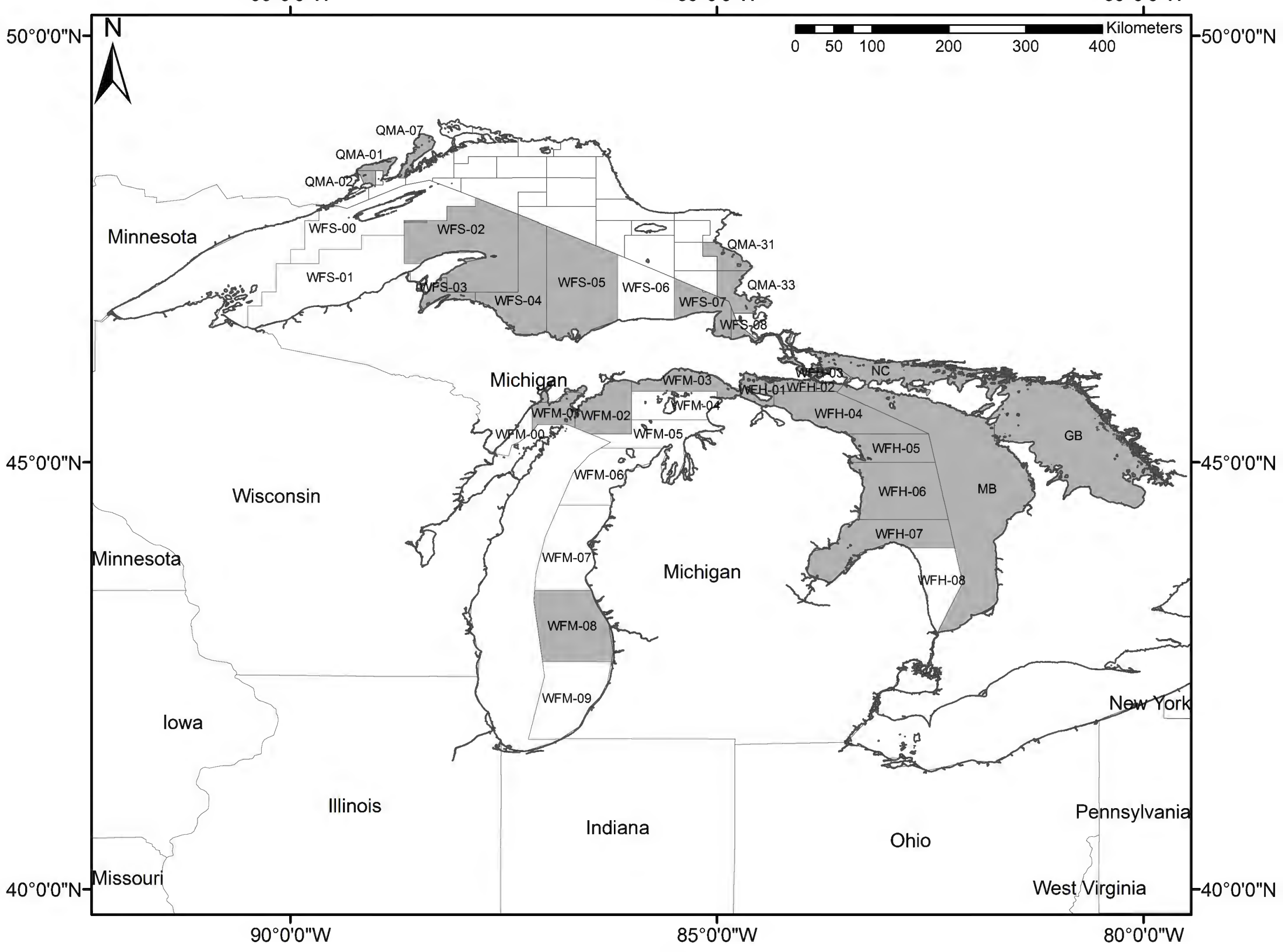




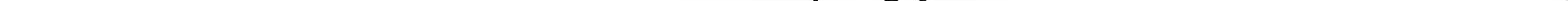



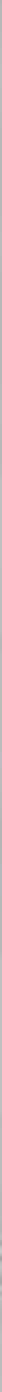

b)

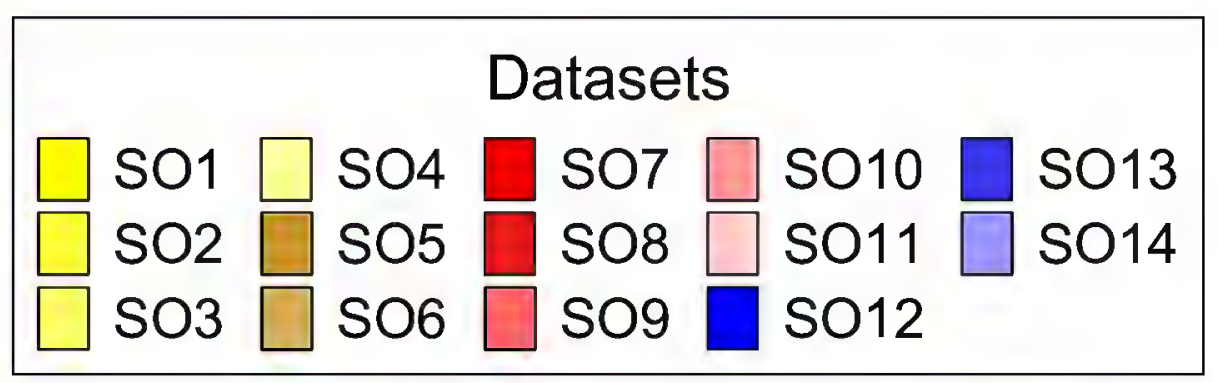

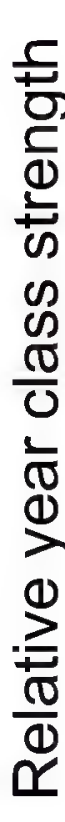

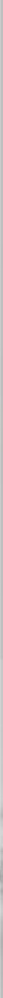

c)

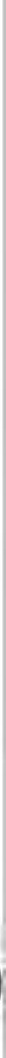


a)

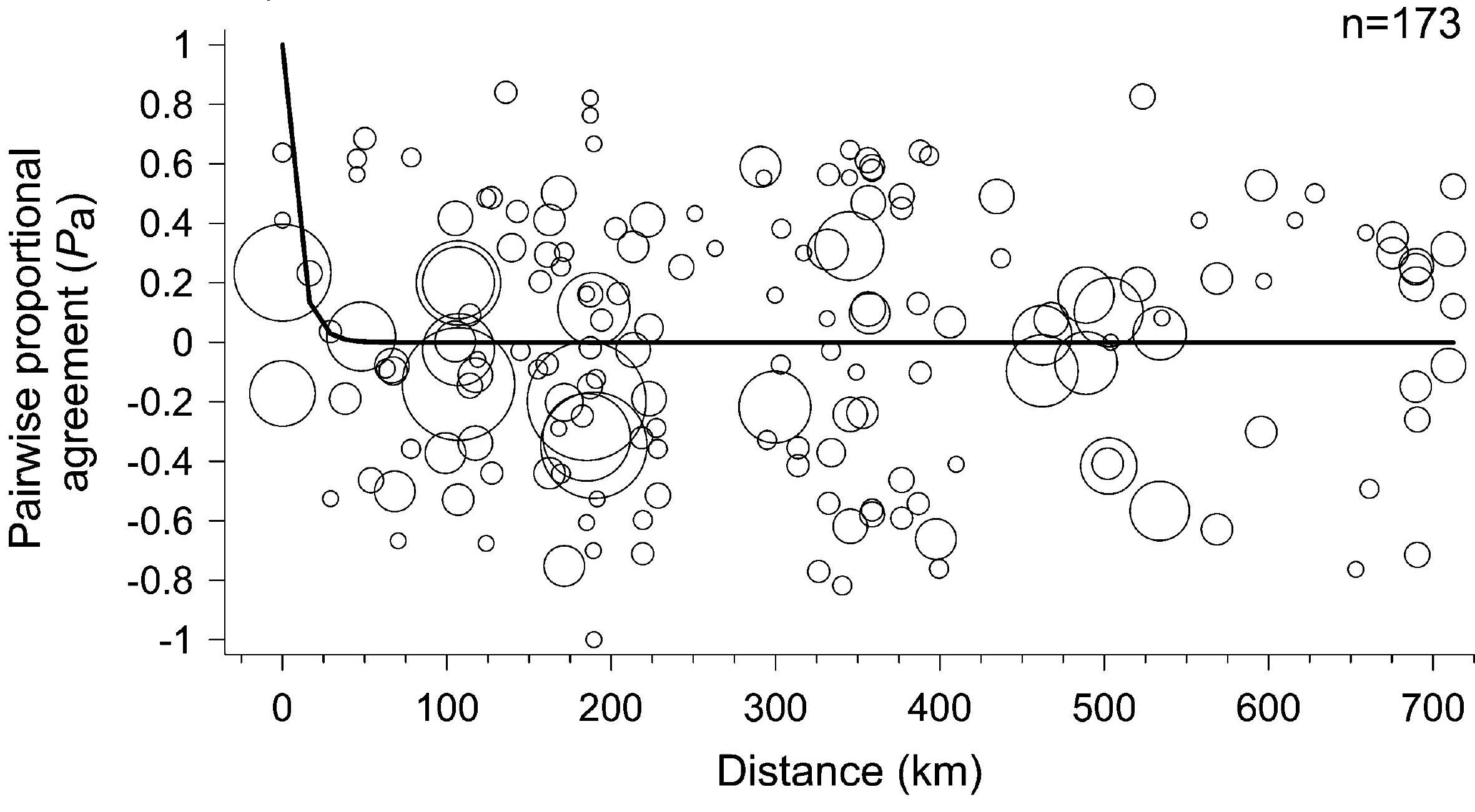

b)

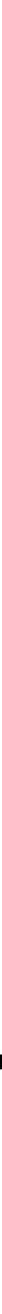

c)

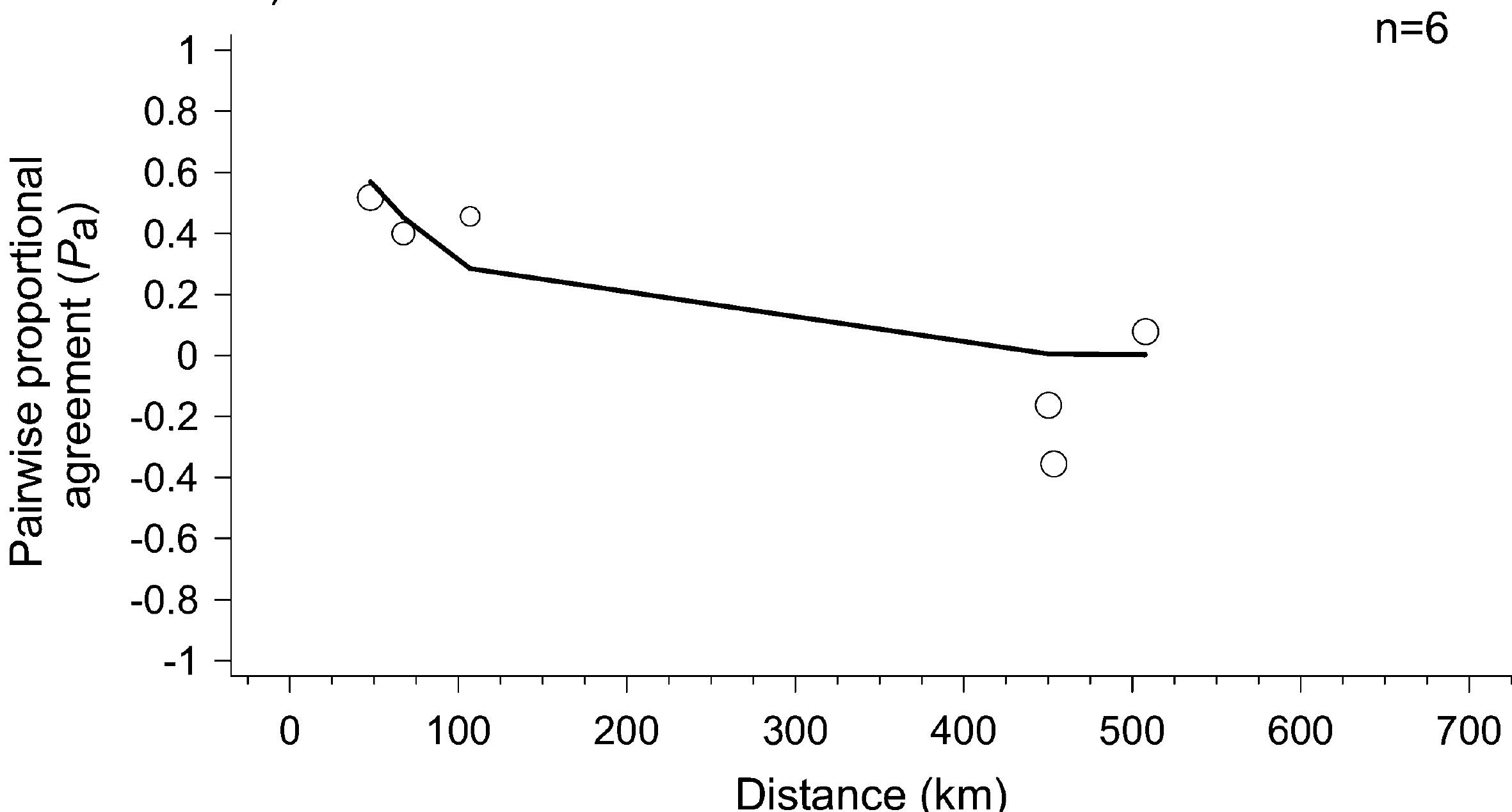




\section{Tables}

\section{Table 1}

The 23 datasets used in an analysis of recruitment synchrony in lake whitefish that were aged using scales. For source, OMNR=Ontario Ministry of Natural Resources, CORA=Chippewa Ottawa Resource Authority, and MIDNR=Michigan Department of Natural Resources. For management unit, WFH = Whitefish Huron, GB=Georgian Bay, MB=Main Basin, NC=North Channel, WFS=Whitefish Superior, QMA=Quota management area. For gear, G=gill nets, and T=trap nets. For sampling, FD=fishery-dependent, and FI=fishery-independent. $\mathrm{n}=$ =sample size for each dataset. Number (n) fish contributing to the analysis.

\begin{tabular}{|c|c|c|c|c|c|c|c|c|}
\hline Dataset & Lake & Source & $\begin{array}{l}\text { Management } \\
\text { Unit }\end{array}$ & Gear & Sampling & $\begin{array}{l}\text { Age range of fish } \\
\text { fully recruited }\end{array}$ & $\begin{array}{l}\text { Year classes } \\
\text { included in analysis }\end{array}$ & $\mathrm{n}$ \\
\hline S1 & Huron & MIDNR & WFH-01 & $\mathrm{T}$ & FD & $4-6$ & $1973-77$ & 1,571 \\
\hline S2 & Huron & MIDNR & WFH -04 & $\mathrm{T}$ & FD & $4-9$ & $1976-83,85-90$ & 3,752 \\
\hline S3 & Huron & MIDNR & WFH -05 & $\mathrm{T}$ & FD & $4-8$ & $1976-89$ & 4,282 \\
\hline S4 & Huron & MIDNR & WFH -06 & $\mathrm{T}$ & FD & $8-9$ & 1989-94 & 7,080 \\
\hline S5 & Huron & MIDNR & WFH -07 & $\mathrm{T}$ & FD & $3-9$ & $1978-82,89,91-95$ & 4,494 \\
\hline
\end{tabular}




\begin{tabular}{|c|c|c|c|c|c|c|c|c|}
\hline S6 & Huron & OMNR & GB & $\mathrm{G}$ & FD & $3-5$ & 1969-80, 84-2007 & 47,794 \\
\hline S9 & Huron & OMNR & GB & $\mathrm{G}$ & FI & $1-5$ & $1978-82,84-2001$ & 13,388 \\
\hline S10 & Huron & OMNR & MB & $\mathrm{G}$ & FI & $1-5$ & 1978-2009 & 22,133 \\
\hline S11 & Huron & OMNR & $\mathrm{NC}$ & $\mathrm{G}$ & FI & $2-3$ & 1988-92 & 1,555 \\
\hline S12 & Superior & CORA & WFS-07 & $\mathrm{G}$ & FD & $5-7$ & $1986-92$ & 4,111 \\
\hline S13 & Superior & CORA & WFS-08 & $\mathrm{G}$ & FD & $6-8$ & $1985-91$ & 2,130 \\
\hline S14 & Superior & CORA & WFS-07 & $\mathrm{T}$ & FD & $5-6$ & $1987-94$ & 3,745 \\
\hline S17 & Superior & MIDNR & WFS-04 & $\mathrm{T}$ & FD & $5-8$ & 1974-95 & 16,045 \\
\hline S18 & Superior & MIDNR & WFS-05 & $\mathrm{T}$ & FD & $5-9$ & $1974-96$ & 13,505 \\
\hline S19 & Superior & OMNR & QMA-01 & G & FD & $6-9$ & 1989-99 & 5,389 \\
\hline S20 & Superior & OMNR & QMA-02 & $\mathrm{G}$ & FD & $7-8$ & 1991-98 & 1,656 \\
\hline
\end{tabular}




\begin{tabular}{llllllll}
\hline S21 & Superior & OMNR & QMA-07 & G & FD & $5-9$ & $1990-99$ \\
S22 & Superior & OMNR & QMA-31 & G & FD & $6-9$ & $1989-95$ \\
S23 & Superior & OMNR & QMA-33 & G & FD & $6-9$ & $1988-98$ \\
\hline
\end{tabular}




\section{Table 2}

The 14 datasets used in an analysis of recruitment synchrony in lake whitefish that were aged using scales and otoliths. For source,

CORA=Chippewa Ottawa Resource Authority. For management unit, WFH=Whitefish Huron, and WFM=Whitefish Michigan. For gear, G=gill nets, and T=trap nets. For sampling, FD=fishery-dependent, and FI=fishery-independent. $\mathrm{n}=$ sample size for each dataset.

\begin{tabular}{lllllllc}
\hline Dataset & Lake & Source & Management & Gear & Sampling & Age range of fish & Year classes \\
& & & & & fully recruited & included in analysis \\
\hline SO1 & Huron & CORA & WFH-01 & G & FD & $7-10$ & $1995-2000$ \\
SO2 & Huron & CORA & WFH-04 & G & FD & $8-11$ & $1991-2000$ \\
SO3 & Huron & CORA & WFH-01 & T & FD & $6-9$ & $1995-2003$ \\
SO4 & Huron & CORA & WFH-02 & T & FD & $7-10$ & $1993-2003$ \\
SO5 & Huron & CORA & WFH-03 & T & FD & $7-9$ & 1930 \\
SO6 & Huron & CORA & WFH-05 & T & FD & $7-11$ & $1999-2003$ \\
SO7 & Michigan & CORA & WFM-01 & T & FD & $7-9$ & $1992-2000$ \\
SO8 & Michigan & CORA & WFM-02 & G & FD & $7-10$ & $1991-2005$ \\
\hline
\end{tabular}




\begin{tabular}{llllllll}
\hline SO9 & Michigan & CORA & WFM-03 & G & FD & $8-9$ & 3,096 \\
SO10 & Michigan & CORA & WFM-03 & G & FI & $3-6$ & $1994-2002$ \\
SO11 & Michigan & CORA & WFM-03 & T & FD & $7-8$ & $1997-2001$ \\
SO12 & Superior & CORA & WFS-07 & G & FD & $5-7$ & $1993-2003$ \\
SO13 & Superior & CORA & WFS-07 & T & FD & $5-8$ & $1994-2003$ \\
SO14 & Superior & CORA & WFS-08 & T & FD & $6-8$ & $1993-2005$ \\
\hline
\end{tabular}




\section{Table 3}

The four datasets used in an analysis of recruitment synchrony in lake whitefish that were aged using otoliths. For source, OMNR=Ontario

Ministry of Natural Resources, and MIDNR=Michigan Department of Natural Resources. For management unit, WFH=Whitefish Huron, and QMA=Quota management area. For gear, $\mathrm{G}=$ gill nets, and T=trap nets. For sampling, $\mathrm{FD}=$ fishery-dependent. $\mathrm{n}=$ sample size for each dataset.

\begin{tabular}{lllllllc}
\hline Dataset & Lake & Source & Management & Gear & Sampling & Age range of fish & Year classes \\
& & & Unit & & & fully recruited & included in analysis \\
\hline O1 & Huron & MIDNR & WFH -06 & T & FD & $11-16$ & $1990,92-98$ \\
O2 & Huron & MIDNR & WFH -07 & T & FD & $9-15$ & $1992-97$ \\
O3 & Superior & OMNR & QMA-01 & G & FD & $12-14$ & $1997-2001$ \\
O4 & Superior & OMNR & QMA-07 & G & FD & $8-10$ & 1,435 \\
\hline
\end{tabular}




\section{Table 4}

The 4 datasets used in an analysis of recruitment synchrony in lake whitefish that were aged using pectoral fin rays. For source,

MIDNR=Michigan Department of Natural Resources. For management unit, WFM=Whitefish Michigan, and WFS=Whitefish Superior. For gear, $\mathrm{T}=$ trap nets. For sampling, FD=fishery-dependent. $\mathrm{n}=$ sample size for each dataset.

\begin{tabular}{|c|c|c|c|c|c|c|c|c|}
\hline Dataset & Lake & Source & $\begin{array}{l}\text { Management } \\
\text { Unit }\end{array}$ & Gear & Sampling & $\begin{array}{l}\text { Age range of fish } \\
\text { fully recruited }\end{array}$ & $\begin{array}{l}\text { Year classes } \\
\text { included in analysis }\end{array}$ & $\mathrm{n}$ \\
\hline P1 & Michigan & MIDNR & WFM-08 & $\mathrm{T}$ & FD & $5-8$ & 1994-2004 & 4,255 \\
\hline $\mathrm{P} 2$ & Superior & MIDNR & WFS-02 & $\mathrm{T}$ & FD & $5-10$ & $1995-98,2001-05$ & 2,856 \\
\hline P3 & Superior & MIDNR & WFS-04 & $\mathrm{T}$ & FD & $6-9$ & $1997-2005$ & 4,824 \\
\hline $\mathrm{P} 4$ & Superior & MIDNR & WFS-05 & $\mathrm{T}$ & FD & $7-8$ & 1997-2004 & 4,059 \\
\hline
\end{tabular}

